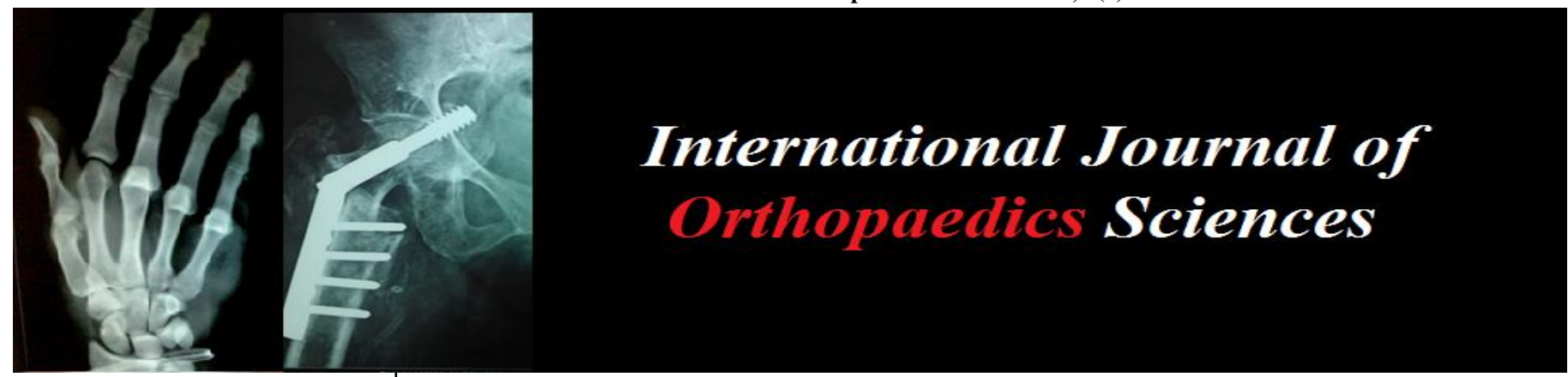

ISSN: $2395-1958$

IJOS 2019; 5(3): 39-45

(C) 2019 IJOS

www.orthopaper.com

Received: 21-05-2019

Accepted: 26-06-2019

Dr. K Chittaranjan

Associate Professor

Melmaruvathur Adhiparasakthi

Institute of Medical College

Science Hospital and Research

Institute, GST Road,

Melmaruvathur, Tamil Nadu,

India

Dr. AT Senthil Kumar

Associate Professor

Melmaruvathur Adhiparasakthi

Institute of Medical College

Science Hospital and Research

Institute, GST Road,

Melmaruvathur, Tamil Nadu,

India

Dr. P Chacko Paul Joseph

Senior Resident Melmaruvathur

Adhiparasakthi Institute of

Medical College Science Hospital

and Research Institute, GST

Road, Melmaruvathur, Tamil

Nadu, India
Correspondence

Dr. K Chittaranjan

Associate Professor

Melmaruvathur Adhiparasakthi

Institute of Medical College

Science Hospital and Research

Institute, GST Road,

Melmaruvathur, Tamil Nadu,

India

\section{Outcome analysis of subtrochanteric fractures fixed with dynamic condylar screw, dynamic hip screw and reconstruction nail}

\author{
Dr. K Chittaranjan, Dr. AT Senthil Kumar and Dr. P Chacko Paul \\ Joseph
}

DOI: https://doi.org/10.22271/ortho.2019.v5.i3a.1505

\section{Abstract}

To determine the rate of union, complications, operative risks and Functional outcome in subtrochanteric fractures treated with DCS, DHS and Reconstruction Nail. To create an algorithm for surgery of choice in various Subtrochanteric fracture patterns. To determine the complications involved in the management of Subtrochanteric fractures.

Keywords: Condylar screw, hip screw, reconstruction nail

\section{Introduction}

Subtrochanteric fractures of the femur account for $10-34 \%$ of all hip fractures ${ }^{[1]}$. These fractures are known to be difficult to treat successfully ${ }^{[2]}$. Certain anatomic, biologic and biomechanical features make this area a unique proposition for the treating surgeon.

The subtrochanteric region of the femur is mainly cortical due to which the area of healing as well as the vascularity is poorer, prolonging the healing time. The forces in this area are up to 1,200 pounds/square inch on the medial cortex leading to immense stresses in the area. The strong muscles on either side of the fracture causes shear at the fracture site ${ }^{[3]}$.

The goal of operative treatment is restoration of normal length and angulation to restore adequate tension to the abductors ${ }^{[5]}$.

This study was based on the results of a retrospective study conducted in our hospital on a consecutive group of 28 patients presenting with subtrochanteric fractures to the casualty department. All 28 fractures were fixed with DCS/DHS or Reconstruction NAIL. The idea of the study is to determine the choice of implant in different subtrochanteric fractures.

\section{Aims \& Objectives}

1. To determine the rate of union, complications, operative risks and Functional outcome in subtrochanteric fractures treated with DCS, DHS and Reconstruction NAIL.

2. To create an algorithm for surgery of choice in various

3. Subtrochanteric fracture patterns.

4. To determine the complications involved in the management of Subtrochanteric fractures.

\section{Materials \& Methods}

The present study consists of 28 adult patients with subtrochanteric fractures of the femur who were treated surgically in Melmaruvathuradhiparasakthi Institute of medical college science hospital and Research Institute from Feb 2018- Feb 2019

The fractures were classified according to Seinsheimer's classification and the cases were followed up at regular intervals postoperatively. This study was conducted with due emphasis for clinical observation and radiological evaluation after surgical management of subtrochanteric fractures fixed with DCS, DHS, Reconstruction nail. 


\section{Inclusion Criteria}

1. Subtrochanteric fractures in adults

\section{Exclusion Criteria}

1. Pediatric subtrochanteric fractures

2. Patients having segmental fractures of the same bone.

3. Pathological fractures

4. Old neglected fractures, fractures with implant failures and compound fractures since the functional outcome cannot be compared to that of fresh closed subtrochanteric fractures

\section{Management of Patient}

As soon as the patient with suspected subtrochanteric fracture was seen, clinical and radiological evaluation was done and admitted to ward after resuscitation and splintage with skeletal traction.

Patient is worked up for surgery with necessary blood and radiological investigations.

All the patients were evaluated for associated medical problems and were referred to respective department and treated accordingly.
Associated injuries were evaluated and treated simultaneously. The patients were operated on elective basis after overcoming the avoidable anaesthetic risks.

\section{Pre-Operative Planning}

The choice of implant for each case is based on:

1. The type of subtrochanteric fracture is classified by Scheinsheimer classification.

2. Achievement of closed reduction.

3. Surgeon's skills and familiarity with the procedure.

In type I, II, III - Intramedullary fixation was adopted if closed reduction of the fracture is achieved. If closed reduction was not achieved on traction table indirect reduction and biological DCS fixation is done.

In type IV, V-Biological DCS fixation is done.

Primary bone grafting was done in all type IV and type V cases where there is devitalization at the fracture site during the surgical procedure when open reduction of the fracture is done.

\section{Operative Technique: Biological DCS Fixation}

Table 1.

\begin{tabular}{|l|l|l|l|l|l|l|l|}
\hline S. No & Implant used & Pain & Flexion loss & Varus, Valgus, Rotatory deformity & Limb length discrepancy & Perfect joint congruency & Results \\
\hline
\end{tabular}

\begin{tabular}{|c|c|}
\hline \multirow{4}{*}{ Excellent } & Flexion loss of less than 10 degrees \\
\cline { 2 - 2 } & No varus, valgus or rotatory deformity \\
\cline { 2 - 2 } & No pain \\
\cline { 2 - 2 } Good & Perfect joint congruity \\
\cline { 2 - 2 } & Lot more than one of the following \\
\cline { 2 - 2 } & Less than 10 degrees varus or valgus deformity \\
\cline { 2 - 2 } & Flexion loss not more than 20 degrees \\
\cline { 2 - 2 } Fair & Minimal pain \\
\hline \multirow{4}{*}{ Failure } & Any of the two criteria in the good category \\
\cline { 2 - 2 } & Flexion less than 90 degrees \\
\cline { 2 - 2 } & Varus or valgus exceeding 15 degrees \\
\cline { 2 - 2 } & Joint incongruency \\
\hline
\end{tabular}

$\mathrm{X}$ ray pelvis was taken in the regular follow up visits to assess fracture union and implant bone interaction Radiological union was said to be achieved on the evidence of obliteration of fracture lines and trabecular continuity between the two fragments on anteroposterior and lateral $\mathrm{x}$ rays in three cortices.

\section{Observation and Results}

The following observations were made from the data collected during the study in Melmaruvathuradhiparasakthi Institute of medical college science hospital and Research Institute from Feb 2018- Feb 2019

Total of 31 cases of subtrochanteric fractures are treated in the department of Orthopaedics, Three patients were diagnosed to have pathological fractures as a result of secondaries and were excluded from the study. 15 patients were treated with DCS, 8 patients were treated with DHS and 5 patients with reconstruction nail. Primary bone grafting was done in 4 patients and secondary bone grafting in 1 patient for delayed union.

\section{Age \& Sex Distribution}

Incidence of subtrochanteric fractures was found to be more common in elderly females especially in $>60$ years age group pts with a mean age of 60.67 years

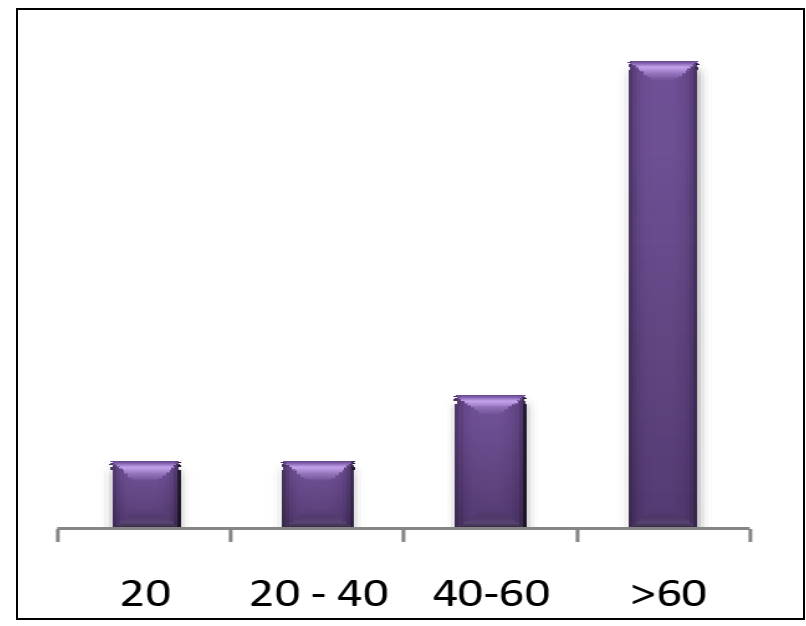

Graph 1: Age Distribution

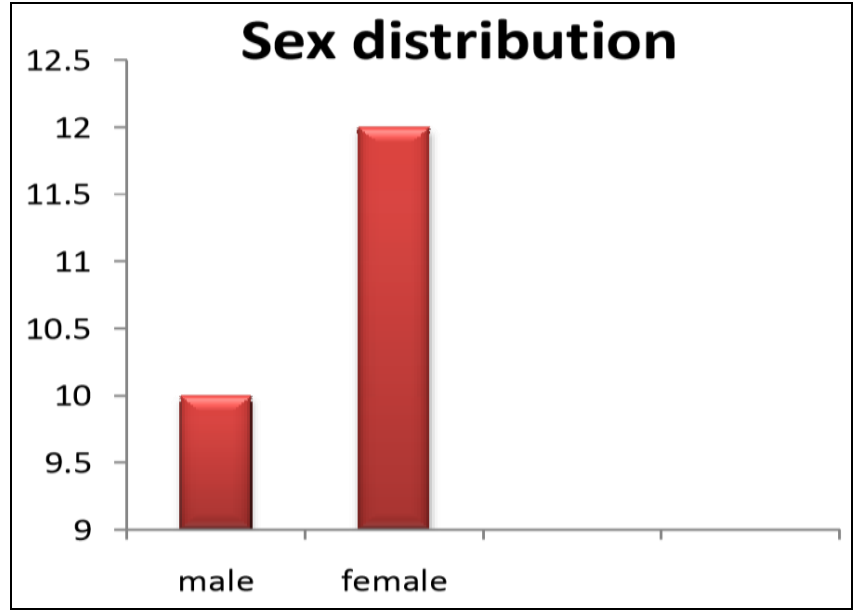

Graph 2: Sex Distribution 
Mode of Injury

Majority of the fractures were secondary to a low velocity injury.

Table 2: Mode of Injury

\begin{tabular}{|c|c|}
\hline Mode of injury & No of cases \\
\hline High velocity & 6 \\
\hline Low velocity & 22 \\
\hline
\end{tabular}

\section{Associated Injuries}

In 4 patients subtrochanteric fracture was a part of polytrauma having other injuries elsewhere in the body and in one patient secondary to a trivial fall.

\section{Classification}

The 28 fractures in our study were classified according to Seinsheimer's classification. In our study we had 9 cases of type II, 10 cases of type III, \&7 cases of type IV and 2 cases of type $\mathrm{V}$ as per Seinsheimer classification

Table 3: Classification of Subtrochanteric fractures

\begin{tabular}{|c|c|}
\hline Seinsheimer's type & No of cases \\
\hline Type II & 9 \\
\hline Type III & 10 \\
\hline Type IV & 7 \\
\hline Type V & 2 \\
\hline
\end{tabular}

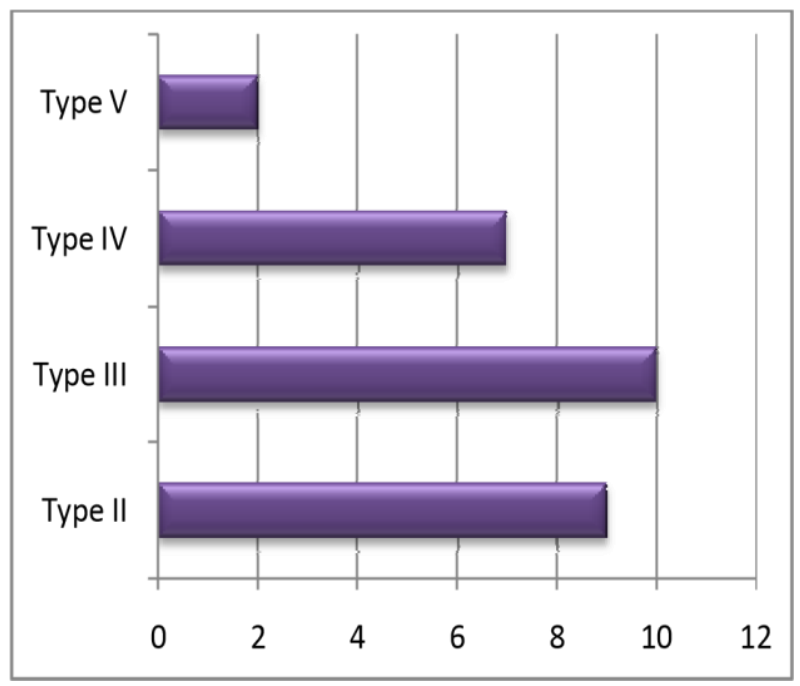

Graph 3: Classification of Fractures

Mode of Fixation: In 8 of 28 cases, DHS fixation was done, in 15 cases DCS fixation was done and Reconstruction nailing was done in 5 cases. The choice of implant was done based on the type of fracture and ability to achieve closed reduction on the fracture table. DHS was the choice of implant for extramedullary fixation in the initial study period. Since the proximal fragment fixation is inadequate and DHS could not be done in a biological manner, DCS became the choice of implant for extramedullary fixation subsequently. In 8 of 28 cases, DHS fixation was done, in 15 cases DCS fixation was done and Reconstruction nailing was done in 5 cases. The choice of implant was done based on the type of fracture and ability to achieve closed reduction on the fracture table.

DHS was the choice of implant for extramedullary fixation in the initial study period. Since the proximal fragment fixation is inadequate and DHS could not be done in a biological manner, DCS became the choice of implant for extramedullary fixation subsequently.

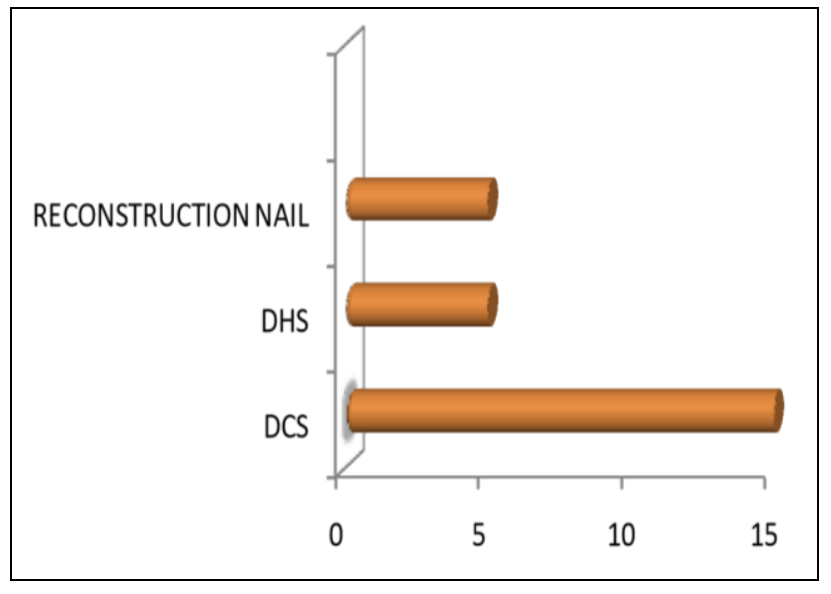

Graph 4: Mode of Fixation

Table 4: Mode of Fixation

\begin{tabular}{|c|c|}
\hline Mode of fixation & No of cases \\
\hline DCS & 15 \\
\hline DHS & 8 \\
\hline Reconstruction nail & 5 \\
\hline
\end{tabular}

Intraoperative Details

All the patients' intraoperative details were noted in terms of duration of surgery, complications and amount of blood loss. Duration of the surgery was longer in the fractures fixed with reconstruction nail than those fixed with DCS and DHS.

\section{Intra Operative Observations}

In 2 of the 5 cases where reconstruction nailing was performed, there was a difficulty in inserting the antirotation screw as it could not be accommodated in the neck.

In case 1 of the study, antirotation screw was not inserted as it was penetrating the superior cortex of the neck and in case 24 a shorter antirotation screw was inserted.

In 2 cases [6, 17] reconstruction nailing was planned pre operatively. Since closed reduction was not able to be achieved biological DCS fixation was chosen.

In 2 cases ${ }^{[8,20]}$, biological DCS fixation was planned. Since proper reduction was not achieved, open reduction of the fracture was done.

\section{Post-Operative Complications}

Open DCS fixation: Implant failure secondary to delayed union -1

Biological DCS fixation: Wound infection - 1, Unicortical break in the neck of femur- 1, Delayed union - 1

DHS fixation: Wound infection - 1

Reconstruction nail fixation: Wound infection - 1, Delayed union- 1

\section{Condition at discharge}

All the patients were mobilized non weight bearing using walker. However in 4 patients mobilisation was delayed due to associated injuries.

\section{Mortality}

One patient (Case 19) died due to acute coronary syndrome one month post operatively which was not related to the surgical event.

\section{Follow up}

All patients were followed up at 4 weeks, 12 weeks and every 
6 weeks thereafter till fracture union is noted and at 6 months. Two patients (Case 14, 22) failed to attend the first follow up and were lost for further follow up and one patient (Case 19) expired one month post operatively due to acute coronary syndrome. One patient (Case 8) had implant failure secondary to delayed union. One patient (case 24) patient had hip pain in the post-operative period due to fracture site instability as the proximal fragment was inadequately fixed with the cephalomedullary screws. One patient (case 16) developed hip pain in the immediate post-operative period and was diagnosed to have Unicortical break in the neck of femur which went on to unite without any intervention and the mobilisation was delayed in view of unicortical break in the neck of femur.

Table 5: Clinical Outcome Using Radford et al Criteria: ${ }^{[38]}$

\begin{tabular}{|c|c|c|c|c|c|c|c|}
\hline Case no & Implant used & Pain & Flexion loss & $\begin{array}{l}\text { Varus/Valgus/ } \\
\text { Rot deformity }\end{array}$ & L.L discrepancy & Joint congruency & Results \\
\hline 1 & Recon nail & $\mathrm{A}$ & A & $\mathrm{A}$ & A & $\mathrm{P}$ & Excellent \\
\hline 2 & DHS & $\mathrm{A}$ & A & $\mathrm{A}$ & $1 \mathrm{~cm}$ & $\mathrm{P}$ & Good \\
\hline 3 & Biological DCS & $\mathrm{A}$ & A & $\mathrm{A}$ & $\mathrm{A}$ & $\mathrm{P}$ & Excellent \\
\hline 4 & Biological DCS & A & A & $10 \mathrm{deg}$ & $2 \mathrm{~cm}$ & $\mathrm{P}$ & Fair \\
\hline 5 & Recon nail & $\mathrm{A}$ & $\mathrm{A}$ & $\mathrm{A}$ & $\mathrm{A}$ & $\mathrm{P}$ & Excellent \\
\hline 6 & Biological DCS & $\mathrm{A}$ & $\mathrm{A}$ & $\mathrm{A}$ & $\mathrm{A}$ & $\mathrm{P}$ & Excellent \\
\hline 7 & DHS & Minimal pain & A & $\mathrm{A}$ & $\mathrm{A}$ & $\mathrm{P}$ & Good \\
\hline 8 & DCS & Disabling pain & Painful restriction & $\mathrm{A}$ & $2 \mathrm{~cm}$ & $\mathrm{P}$ & Failure \\
\hline 9 & DHS & Minimal pain & $\mathrm{A}$ & $10 \mathrm{deg}$ & $\mathrm{A}$ & $\mathrm{P}$ & Fair \\
\hline 10 & Biological DCS & $\mathrm{A}$ & A & $20 \mathrm{deg}$ & A & $\mathrm{P}$ & Good \\
\hline 11 & Biological DCS & $\mathrm{A}$ & A & $\mathrm{A}$ & $\mathrm{A}$ & $\mathrm{P}$ & Excellent \\
\hline 12 & DHS with bone grafting & $\mathrm{A}$ & A & 30 deg & $1 \mathrm{~cm}$ & $\mathrm{P}$ & Fair \\
\hline 13 & Biological DCS & $\mathrm{A}$ & A & A & $\mathrm{A}$ & $\mathrm{P}$ & Excellent \\
\hline 14 & Biological DCS & A & A & A & $\mathrm{A}$ & $\mathrm{P}$ & LIF \\
\hline 15 & Biological DCS & A & A & A & A & $\mathrm{P}$ & Excellent \\
\hline 16 & Biological DCS with bone grafting & Minimal pain & $30 \mathrm{deg}$ & $20 \mathrm{deg}$ & $1 \mathrm{~cm}$ & $\mathrm{P}$ & Failure \\
\hline 17 & Biological DCS & $\mathrm{A}$ & A & $\mathrm{A}$ & $\mathrm{A}$ & $\mathrm{P}$ & Excellent \\
\hline 18 & Biological DCS & Minimal pain & $30 \mathrm{deg}$ & $\mathrm{A}$ & $\mathrm{A}$ & $\mathrm{P}$ & Fair \\
\hline 19 & DHS with bone grafting & A & A & A & $\mathrm{A}$ & $\mathrm{P}$ & LIF \\
\hline 20 & DCS & $\mathrm{A}$ & $20 \mathrm{deg}$ & $\mathrm{A}$ & $\mathrm{A}$ & $\mathrm{P}$ & Good \\
\hline 21 & Biological DCS & $\mathrm{A}$ & $\mathrm{A}$ & $\mathrm{A}$ & A & $\mathrm{P}$ & Excellent \\
\hline 22 & DHS locking plate with bone grafting & $\mathrm{A}$ & A & $\mathrm{A}$ & $\mathrm{A}$ & $\mathrm{P}$ & LIF \\
\hline 23 & DHS & $\mathrm{A}$ & $30 \mathrm{deg}$ & $10 \mathrm{deg}$ & $\mathrm{A}$ & $\mathrm{P}$ & Fair \\
\hline 24 & recon nailing & Minimal pain & $20 \mathrm{deg}$ & $\mathrm{A}$ & $\mathrm{A}$ & $\mathrm{P}$ & Fair \\
\hline 25 & DHS & Minimal pain & $\mathrm{A}$ & $\mathrm{A}$ & $\mathrm{A}$ & $\mathrm{P}$ & Good \\
\hline 26 & Recon nail & Minimal pain & A & $\mathrm{A}$ & $\mathrm{A}$ & $\mathrm{P}$ & Good \\
\hline 27 & Biological DCS & A & A & A & A & $\mathrm{P}$ & Excellent \\
\hline 28 & Recon nail & Minimal pain & A & $\mathrm{A}$ & $1 \mathrm{~cm}$ & $\mathrm{P}$ & Fair \\
\hline
\end{tabular}

\section{Union in Weeks}

Biological DCS fixation- 15.4 weeks (10-32 weeks) DHS fixation- 16.1 weeks (14-20 weeks) Reconstruction nail fixation- 16.8 weeks (12-30 weeks) One patient (Case 28) in reconstruction nail fixation group went for delayed union (30 weeks).By eliminating this case from the group there is a significant improvement in the standard deviation (7.56 to 1.91) and the average time for union in the remaining cases is 13.5 weeks. One patient (Case 27) in the DCS fixation group went for delayed union (32 weeks). By eliminating this case from the group the average time for union in the remaining patients is 15 weeks.

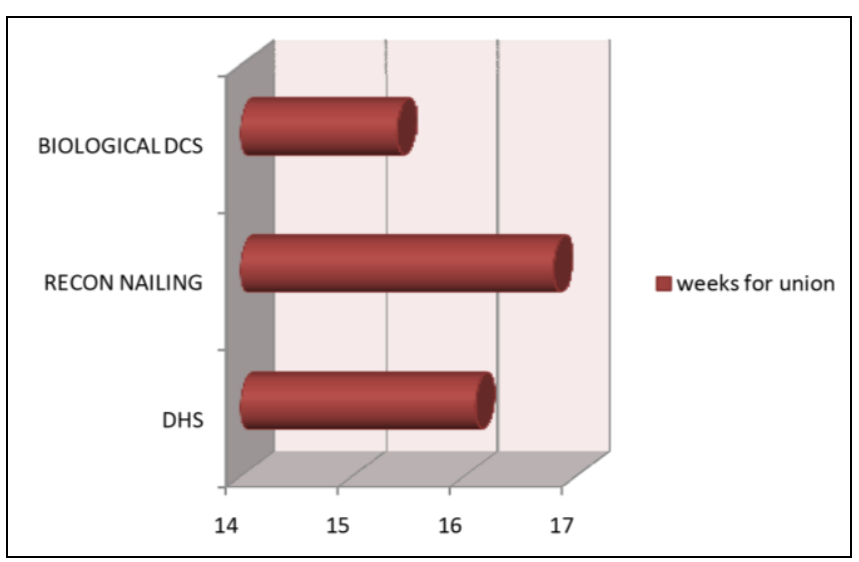

Graph 5: Union in Weeks

\section{Discussion}

Subtrochanteric fractures of the femur demand a special consideration in orthopedic traumatology, given the high rate of complications associated with their management due to the high loading forces and immense stresses in this area.

Even though better reduction techniques and biomechanically improved implants and improved fracture fixation techniques have improved the functional outcome of these fractures ideal implant for these fractures is still not defined. No single implant is ideal for all types of subtrochanteric fractures. An ideal implant should achieve stable fixation with no interference with the vascularity and hold the fracture till it unites. Fixation is a race between fracture healing and implant failure. Irrespective of the mode of fixation emphasis is laid on the medial cortex reconstitution as described in the study by Senter B et al. ${ }^{[56]}$ but in many of these fractures, reconstruction of solid medial wall is not possible, due to comminution or bone loss where autogenous bone grafting is suggested. This study analyses various aspects needed to be addressed while treating subtrochanteric fractures and determine the choice of implant in different subtrochanteric fractures.

\section{Reconstruction Nail Fixation}

Intramedullary devices require less surgical exposure, enable early weight bearing and exert less biomechanical stresses (as the lever arm is moved medially) ${ }^{[39-41]}$ However technical difficulties are observed in upto $63 \%$ of the cases. ${ }^{[42,43]}$ Lavell 
David $\mathrm{G}$ et al described Reconstruction nailing as a technically demanding procedure and suggested plate and screw fixation as the best option ${ }^{[1]}$.

We had difficulty in putting the derotation screw in 2 out of 5 cases $(40 \%)$ compared to that of a study by Fogagnolo et al where $23.4 \%$ of intraoperative technical and mechanical complications were noted. When intramedullary devices cannot be used for technical reasons dynamic condylar screw provides a reasonable option.

In 2 cases where we had planned intramedullary nailing, procedure was abandoned as we were unable to achieve a perfect closed reduction and hence converted to DCS fixation. Average time for union was 16.8 weeks compared to 15.1 weeks in a study by Lee et al. ${ }^{[44]}$ with $60 \%$ excellent to good functional outcome. We had achieved $100 \%$ union rate with one case of delayed union simulating the results of a study by Gibson et al. ${ }^{[45]}$.

\section{Reconstruction Nail is Recommended In}

- Type I, II \& III subtrochanteric fractures when closed reduction is achieved.

Recon nail is not preferred in severe communited fractures and fractures with trochanteric extension as we feel that the hold of the implant on the proximal fragment is not adequate and also it is an observation that the head screws do not lock onto the nail and hence compromising the stability of the fixation. Recon nail is not preferred in severe communited fractures and fractures with trochanteric extension as we feel that the hold of the implant on the proximal fragment is not adequate and also it is an observation that the head screws do not lock onto the nail and hence compromising the stability of the fixation.

\section{DHS Fixation}

Some decades ago, a sliding-screw plate system came into wider use even in subtrochanteric fractures because of the successful treatment of stable trochanteric fractures ${ }^{[48]}$. In unstable per- and sub-trochanteric fractures, however, the system has been reported to involve high failure rates ${ }^{[46-48]}$ as it may not be possible to supplement the sliding screw with additional cortical screws in the proximal fragment of a subtrochanteric fracture [50]. Biologically, extensive comminution and fragment devitalisation compromises bone healing ${ }^{[49]}$ Extensive dissection at the fracture site is required to place the DHS implant. Even though we had achieved $100 \%$ union rate with average time for fracture healing of
16.1 weeks with no complications and $50 \%$ good functional outcome, the implant has its limitations of inadequate proximal fixation and it could not be done in a biological manner.

\section{DCS Fixation}

Comminuted subtrochanteric femoral fractures are often caused by high-energy trauma ${ }^{[51,52]}$. Fractures may extend into the greater and the inter-trochanteric regions ${ }^{[49]}$ Open reduction further devitalizes fragments, damages the vascular supply or soft tissues, and increases the risks of non-union, infection, and implant failure ${ }^{[51]}$ whereas indirect reduction does not ${ }^{[49]}$.

One case of implant failure $(12.5 \%)$ is observed in fractures fixed with DCS by open reduction compared to failure rates of 20 to $23 \%$ in different studies ${ }^{[53,54]}$ The likely cause for delayed union and implant failure was not doing a primary bone grafting in an extensively communited fracture.

In one case patient was found to have a Unicortical break in the neck of femur secondary to fixation with a short head screw which united without any intervention and mobilisation was delayed in this patient.

Vaidya et al. ${ }^{[55]}$ evaluated the use of DCS and biological reduction techniques for subtrochanteric fractures and concluded the use of indirect reduction techniques instead of anatomic open reduction has proven to be successful, especially in comminuted fractures.

DCS fixation when done biologically have shown better results compared to those fractures fixed with Reconstruction nail ${ }^{[44]}$.

$100 \%$ union rate is observed in cases where biological DCS fixation with 9 out of 13 patients had excellent to good results compared to the results obtained in the study by Vaidya et al. [55] Average time for radiological union in cases where biological fixation is done was 110 days compared to 91 days in the study by Neher et al.

It could be a preferred implant of choice in:

- $\quad$ Type IV and type V subtrochanteric fractures.

- Revision surgeries.

DCS fixation should be done in a biological manner without opening the fracture site whenever reduction is achieved by indirect means to avoid the need for bone grafting and devitalisation of the fracture fragments.

In the management of subtrochanteric fractures ideal implant selection is important for a better functional outcome. 


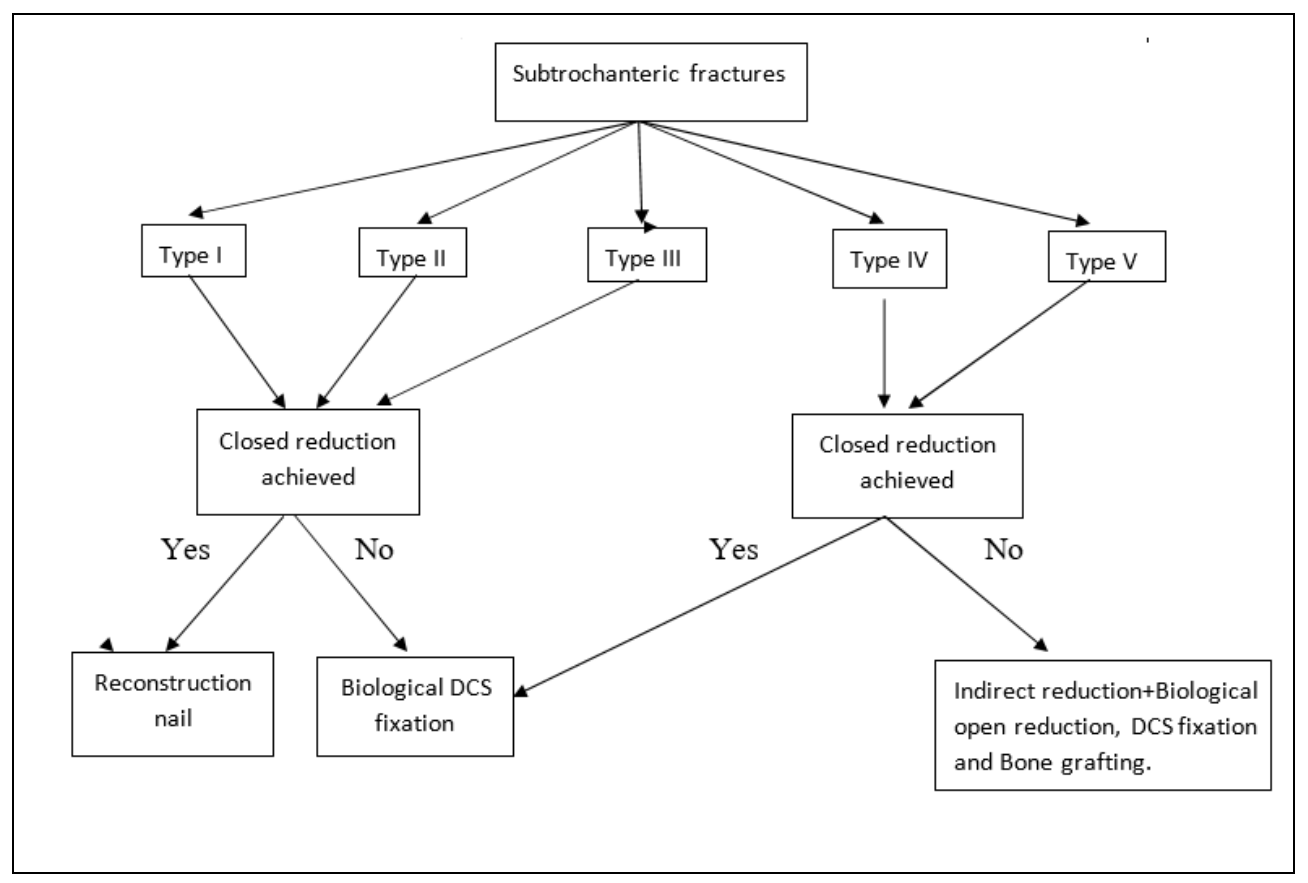

\section{Limitations}

- Numbers are small to make a scientific comparison.

- Large no of cases are required to assess the reliability of the proposed algorithm.

\section{Conclusion}

- No single implant is ideal for all subtrochanteric fractures

- Intramedullary implant can be used in type I, II \& III fractures if closed reduction is achieved.

- Biological DCS fixation is superior to other modes of fixation in type IV \& V subtrochanteric fractures.

- Biological DCS fixation reduces the need for bone grafting in communited subtrochanteric fractures.

- Stable internal fixation using indirect reduction techniques rather than anatomic reduction enhances healing potential.

\section{Reference}

1. David G. Lavelle. Fractures and dislocations of the hip. In: Canale ST, Beaty JH, eds. Campbell's operative orthopaedics, $11^{\text {th }}$ Edn. Philadelphia, Pa: Mosby Elsevier; 2007, 52.

2. Asher MA, Tippet JW, Rockwood CA, Zilber S. Compression Fixation of subtrochanteric fractures. CORR No 117,

3. Sims SH. Treatment of complex fractures. Orthop Clin North Am 33(1):1-12

4. Wadell JP. Subtrochanteric fractures of femur: a review of 130 patients. J Trauma 19(8):582-92

5. Toni M, Mclaunn, Ericka A. Lawler: Treatment Modalities for subtrochanteric fractures in elderly. Lippincott Williams and Wilkins Inc. Philadelphia. Techniques in Orthopaedics. 2004; 19(3):197-213

6. Kwok-sui Leung. Subtrochanteric fractures. In: Robert W Bucholz, James D Heckman, Charles M Court-Brown, eds. Rockwood and Green's Fractures in Adults; $6^{\text {th }}$ edition. Philadelphia, Pa: Lippincott Williams \& Wilkins; 2006, 46

7. Koch JC. The laws of bone architecture. Am J Anat. $1917 ; 21: 177-298$.
8. Bergman GD, Winquist RA, Mayo KA, Hansen Jr ST. Subtrochanteric fracture of the femur: Fixation using the Zickel nail. J Bone Joint Surg Am. 1987; 69:1032-40.

9. Robey LR. Intertrochanteric and subtrochanteric fractures of the femur in the Negro. J Bone Joint Surg Am. 1956; 38:1301-12.

10. Velasco RU, Comfort T. Analysis of treatment problems in subtrochanteric fractures of the femur. J Trauma. 1978; 18:513-22.

11. Waddell JP. Subtrochanteric fractures of the femur: A review of 130 patients. J Trauma. 1979; 19:585-92.

12. Michelson JD, Myers A, Jinnah R et al. Epidemiology of hip fractures among the elderly: Risk factors for fracture type. Clin Orthop. 1995; 311:129-35.

13. Habernek H, Schmid L, Frauenschuh E. Sport related proximal femoral fractures; a retrospective review of 31 cases treated in an eight year period. Br J Sports Med. 2000; 34:54-8.

14. Kenneth j Koval, Joseph D. Zuckerman. Hip fractures-A practical guide to management, 191-252

15. Fielding JW, Magliato HJ. Subtrochanteric fractures. Surg Gynecol Obstet. 1966; 122:555-69.

16. Seinsheimer F III. Subtrochanteric fractures of the femur. J Bone Joint Surg. 1978; 60A:300- 6.

17. Perren SM. Evolution of the internal fixation of long bone fractures. The scientific basis of biological internal fixation: choosing a new balance between stability and biology. J Bone Joint Surg (Br). 2002; 84(8):1093-110.

18. Russell-Taylor classification of subtrochanteric fractures. Skeletal Trauma. 1998; 2:1891-7.

19. Chapman MW. The role of intramedullary nailing in fracture management. In: Browner BD. Edwards CD, Eds. The science and practice of intramedullary nailing. Philadelphia: Lea \& Febiger, 1987, 17-23.

20. Mahomed N, Harrington I, Kellam J, Maistrelli G, Hearn I, Vroemen J. Biomechanical analysis of the gamma nail and sliding hip screw. Clin Orthop. 1994; 304:280.

21. Shrinand V, Vaidya a, Devesh B. Dholakia a, Anirban Chaterjee $b$. The use of a dynamic condylar screw and biological reduction techniques for subtrochanteric femur fracture, Injury, Int. J Care Injured. 2003; 34:123-8 
22. Vanderschot P, Verheyen L, Broos P. A review on 161 subtrochanteric fractures-risk factors influencing outcome: age, fracture pattern and fracture level. Unfallchirurg 1995; 98(5):265-71.

23. Stephen H. Sims, MD. Orthopaedic Clinic of North America Jan. 2002; 33(1).

24. Kinast C, Bolhofner BR, Mast JW, Ganz R. Subtrochanteric fractures of the femur: results of treatment with the 95 -degree condylar blade plate. Clin Orthop. 1989; 238:122-30.

25. Kulkarni SS, Moran CG. Results of dynamic condylar screw for subtrochanteric fractures. Injury. 2003; 34(2):117-22. 